\title{
Formulation and evaluation of mixed matrix gastro- retentive drug delivery for famotidine
}

\author{
Dasharath M Patel, Mehul J Patel, Ankit N Patel, Chhagan N Patel \\ Department of Pharmaceutics and Pharm Technology, Shri Sarvajanik Pharmacy College, Mehsana, Gujarat, India
}

\begin{abstract}
Introduction: Present investigation describes an influence of ratio of Gelucire 43/01 (hydrophobic) to hydroxypropyl methylcellulose K4M (HPMC K4M) (hydrophilic) and different fillers on release of famotidine from gastro-retentive tablets using $3^{2}$ full factorial design. Ratio of Gelucire 43/01 to HPMC K4M $\left(X_{1}\right)$ and the type of filler $\left(X_{2}\right)$ were selected as independent variables while buoyancy lag time $(B L T)$, drug release at $1 \mathrm{~h}\left(\mathrm{Q}_{1}\right), 6 \mathrm{~h}\left(\mathrm{Q}_{6}\right)$, and the $12 \mathrm{~h}\left(\mathrm{Q}_{12}\right)$ were selected as dependent variables. Materials and Methods: Gastro-retentive tablets of famotidine were prepared by a solvent free melt granulation technique using Gelucire $43 / 01$ as a hydrophobic meltable binder. HPMC K4M and sodium bicarbonate were used as matrixing agent and gas-generating agent, respectively. Prepared tablets were evaluated for in vitro dissolution, in vitro buoyancy, friability, hardness, drug content and weight variation. Dissolution data were fitted to various models to ascertain kinetics of drug release. The data were analyzed using regression analysis and analysis of variance. Results: All formulations $\left(\mathrm{F}_{1}-\mathrm{F}_{9}\right)$ showed floating within $3 \mathrm{~min}$ and had total floating time of more than $12 \mathrm{~h}$. It was observed that a type of filler and the ratio of Gelucire 43/01 to HPMC K4M had significant influence on buoyancy lag time $(P=0.037)$ and $Q_{6}(P=0.011)$, respectively without significant influence on $\mathrm{Q}_{1}$ and $\mathrm{Q}_{12}$. Conclusion: Formulation $\mathrm{F}_{5}$ was selected as an optimum formulation as it showed more similarity in dissolution profile with theoretical profile (Similarity factor, $f_{2}=83.01$ ). The dissolution of batch $F_{5}$ can be described by zero order kinetics $\left(r^{2}=0.9914\right)$ with anomalous (non-Fickian) diffusion as a release mechanism ( $\mathrm{n}=0.559)$. The difference observed in in vitro release profile after temperature sensitivity study at $40^{\circ} \mathrm{C}$ for 1 month was insignificant.
\end{abstract}

Key words: Buoyancy lag time, full factorial design, Gelucire 43/01, melt granulation

\section{INTRODUCTION}

Frequency of drug administration in a conventional dosage form depends upon the elimination half-life of drug $\left(t_{1 / 2}\right){ }^{[1]}$ Controlled release dosage form reduces a frequency of drug administration and the fluctuations in plasma drug concentration. A gastroretentive drug delivery system that can be retained in the stomach is useful for controlled release and for site specific drug absorption. There are number of approaches used to prolong gastric retention time, such as floating drug delivery system, swelling and

\section{Address for correspondence:}

Dr. Dasharath M. Patel,

Department of Pharmaceutics and Pharm Technology, Shri Sarvajanik Pharmacy College, Near- Arvind Baug, Mehsana- 384 001, Gujarat, India. E-mail: drdmpatel1971@gmail.com

\begin{tabular}{|l|l|}
\hline \multicolumn{2}{|c|}{ Access this article online } \\
\hline Quick Response Code: & Website: \\
& www.jpionline.org \\
\cline { 2 - 2 } & DOI: \\
\hline
\end{tabular}

expanding system, polymeric bioadhesive systems, modified shape systems, high density system and raft formation. ${ }^{[2-4]}$

Famotidine is histamine receptor $\left(\mathrm{H}_{2}\right)$ antagonist used in a treatment of zollinger ellision syndrome, gastro esophageal reflux disease and peptic ulcer in the dose ranging from 10 to $80 \mathrm{mg} .{ }^{[5]}$ Half life of a drug is about $2.5-3.5 \mathrm{~h}$ and the oral bioavailability is $45 \pm 14 \%$ indicating its promising candidature for sustained release formulation. ${ }^{[6]}$ Oral treatment of gastric disorders with $\mathrm{H}_{2}$ receptor antagonist such as famotidine or ranitidine in combination with antacids promotes local delivery of these drugs to the receptor of parietal cell wall. Local delivery also increases a bioavailability and the efficacy of drug to reduce acid secretion. ${ }^{[7]}$

Hydrophilic matrices are widely used and accepted for sustained release but a drug release from such matrices is time dependent with very less possibility of zero order drug release. ${ }^{[8]}$ Initially, a drug present at surface of the matrix is released quickly, yielding a burst effect, then with time, as the diffusion path length increases the release rate is progressively reduced. Several authors have described various approaches to limit the burst effect from monolithic matrix systems in order to obtain zero order drug release ${ }^{[9-13]}$ Conte and co-workers designed a multilayered hydrophilic matrix system (GeomatrixR) to obtain zero order 
drug delivery by coating one or both sides of the matrix tablet with HPMC based barrier. ${ }^{[14-16]}$ Krogel and Bodmeier invented a system composed of hydrophilic matrix tablet placed in impermeable polypropylene cylinder, reducing drug release to the open ends of the cylinder. ${ }^{[17]}$ Colombo et al. described a modulation of drug release by physically restricting matrix swelling through partial coating of the matrix with impermeable cellulose acetate propionate film. ${ }^{[18]}$ Danckwerts developed a core-in-cup tablet consisting of inert cup of ethylcellulose and carnauba wax into which drug-containing matrix layer was compressed, thus leading to matrix with only one side in contact with the surrounding medium. ${ }^{[19]}$ Although these devices are able to reduce drug release, they have in common that their production process is complicated and time-consuming. Hydrophobic polymers are most suitable matrix formers to limit the burst effect from monolithic matrix system containing hydrophilic polymers. ${ }^{[20]}$

So the purpose of this research was to prepare a mixed matrix gastroretentive tablet of famotidine using Gelucire 43/01 and hydroxylpropyl methylcellulose K4M (HPMC K4M). A $3^{2}$ full factorial design was employed to investigate effect of two independent variables, i.e. a ratio of Gelucire 43/01 to hydroxypropyl methylcellulose (HPMC K4M) and the type of filler (lactose, dicalcium phosphate, microcrystalline cellulose) on the dependent variables, i.e. buoyancy lag time (BLT), $\mathrm{Q}_{1}$, $\mathrm{Q}_{6}$ and $\mathrm{Q}_{12}$ (\% drug release after $1,6,12 \mathrm{hr}$, respectively).

\section{MATERIALS AND METHODS}

\section{Materials}

Famotidine was received as a gift sample from Mann Pharmaceuticals Ltd, Mehsana, India. Hydroxypropyl methylcellulose K4M (HPMC K4M) was obtained from Yarrow Chem. Products, Mumbai, India. Gelucire 43/01 was obtained from Gattefosse, France. Sodium bicarbonate and magnesium stearate were obtained from Shakti Chemicals, Mehsana, India. Lactose and talc were obtained from Chemdyes Corporation, Ahmedabad, India. All other materials and chemicals used were of either pharmaceutical or analytical grade.

\section{Methods}

\section{Preparation of famotidine floating tablets by melt granulation}

Gelucire $43 / 01$ was melted in a large petridish at $50^{\circ} \mathrm{C}$ and the required quantity of famotidine was added to melted mass. Previously prepared geometric mixture of HPMC K4M and sodium bicarbonate was added to famotidine - Gelucire 43/01 mixture and stirred well to mix. This mass was removed from a hot plate and subjected to scrapping until it attained room temperature. The coherent mass was passed through 22 mesh and the resulting granules were resifted using 44 meshes to separate fines. The granules were collected and mixed with talc (2\%) and magnesium stearate (1\%). The lubricated blend was compressed using round tooling on Rimek-I rotary tablet machine (Karnavati
Engineering, Kadi, India). Compression pressure was adjusted to obtain tablets with hardness in a range of $2-3 \mathrm{~kg} / \mathrm{cm}^{2}$.

\section{In vitro buoyancy studies}

The in vitro buoyancy of the tablets was studied at $37 \pm 0.5^{\circ} \mathrm{C}$ in $100 \mathrm{ml}$ of simulated gastric fluid (SGF) at $\mathrm{pH} 1.2$ without pepsin (USP). The duration of tablet floatation was observed visually. ${ }^{[21]}$

\section{In vitro dissolution study}

The in vitro dissolution study of famotidine tablets was performed using USP apparatus (model TDT-08T, Electrolab, Mumbai, India) fitted with paddle $(50 \mathrm{rpm})$ at $37 \pm 0.5^{\circ} \mathrm{C}$ using SGF $(\mathrm{pH} 1.2 ; 900 \mathrm{~mL})$ as a dissolution medium. At predetermined time intervals, $10-\mathrm{mL}$ samples were withdrawn, filtered through a $0.45 \mu \mathrm{m}$ membrane filter, diluted and assayed at $265 \mathrm{~nm}$ using Shimadzu UV 1800 double-beam spectrophotometer (Shimadzu, Kyoto, Japan). Cumulative percentage drug release was calculated using an equation obtained from calibration curve.

\section{Preliminary screening}

Preliminary screening was performed to optimize amount of sodium bicarbonate and total amount of polymer in a formulation. Tablets were prepared by melt granulation method using $40 \%$ of total concentration of polymers (Gelucire 43/01 and HPMC K4M in ratio of 3:5) and varying amount of sodium bicarbonate $(5 \%, 10 \%, 15 \%)$ as shown in Table 1 . Prepared tablets were tested for in vitro buoyancy studies and intactness. Tablets were prepared using $10 \%$ of sodium bicarbonate and varying amount $(30 \%, 40 \%, 50 \%)$ of polymer (Gelucire 43/01 and HPMC $\mathrm{K} 4 \mathrm{M}$ in ratio of 3:5) as shown in Table 2. Tablets prepared with varying amount of polymer were tested for in vitro buoyancy studies, intactness and in vitro drug release.

\section{Optimization of variables using full factorial design}

A $3^{2}$ randomized full factorial design was used in present study. In this design 2 factors were evaluated, each at 3 levels, and experimental trials were performed for all 9 possible combinations. Ratio of Gelucire 43/01 to HPMC K4M ( $\left.\mathrm{X}_{1}\right)$ and type of filler

\begin{tabular}{|c|c|c|c|}
\hline \multirow[t]{2}{*}{ Name of ingredient } & \multicolumn{3}{|c|}{ Quantity in mg/tablet } \\
\hline & Co1 & $\mathrm{CO} 2$ & $\mathrm{CO3}$ \\
\hline Famotidine & 40 & 40 & 40 \\
\hline Gelucire 43/01 & 30 & 30 & 30 \\
\hline HPMC K4M & 50 & 50 & 50 \\
\hline Sodium bicarbonate & 10 & 20 & 30 \\
\hline Lactose & 70 & 60 & 50 \\
\hline Talc & 4 & 4 & 4 \\
\hline Magnesium stearate & 2 & 2 & 2 \\
\hline Buoyancy lag time & $>5 \mathrm{~min}$ & $58 \mathrm{sec}$ & $30 \mathrm{sec}$ \\
\hline Total buoyancy time & $>24 \mathrm{hr}$ & $>24 \mathrm{hr}$ & $<10 \mathrm{hr}$ \\
\hline Intactness & Intact & Intact & Broken \\
\hline
\end{tabular}

HPMC indicates hydroxypropyl methylcellulose; the average weight of tablet is $206 \mathrm{mg}$ 
(lactose, microcrystalline cellulose, dicalcium phosphate) $\left(\mathrm{X}_{2}\right)$ were chosen as independent variables while BLT, percentage drug release in $1 \mathrm{~h}\left(\mathrm{Q}_{1}\right), 6 \mathrm{~h}\left(\mathrm{Q}_{6}\right)$, and $12 \mathrm{~h}\left(\mathrm{Q}_{12}\right)$ were taken as dependent variables. The formulation layout for the factorial design batches $\left(F_{1}-F_{9}\right)$ is shown in Table 3. Prepared formulations were evaluated for assay, friability and hardness in addition to in vitro buoyancy and release study. Results of this evaluation are shown in Table 4.

\section{Kinetic modeling of dissolution data}

Dissolution profile of all batches were fitted to various models such as zero order, first order, Higuchi, ${ }^{[22]}$ Hixon Crowell, ${ }^{[23]}$

\begin{tabular}{lccc}
$\begin{array}{l}\text { Table 2: Formulation of famotidine floating } \\
\text { tablets using different amount of polymers }\end{array}$ \\
\hline Name of ingredient & \multicolumn{3}{c}{ Quantity in mg/tab } \\
\cline { 2 - 4 } & PO1 & PO2 & PO3 \\
\hline Famotidine & 40 & 40 & 40 \\
Gelucire 43/01 & 22.5 & 30 & 35 \\
HPMC K4M & 37.5 & 50 & 65 \\
Sodium bicarbonate & 20 & 20 & 20 \\
Lactose & 80 & 60 & 40 \\
Talc & 4 & 4 & 4 \\
Magnesium stearate & 2 & 2 & 2 \\
Buoyancy lag time & $52 \mathrm{sec}$ & $58 \mathrm{sec}$ & $70 \mathrm{sec}$ \\
Total buoyancy time & $>24 \mathrm{hr}$ & $>24 \mathrm{hr}$ & $>24 \mathrm{hr}$ \\
Intactness & Intact & Intact & Intact \\
\hline
\end{tabular}

HPMC indicates hydroxypropyl methylcellulose; the average weight of tablet is $206 \mathrm{mg}$.
Korsemeyer, and Peppas ${ }^{[24]}$ to ascertain kinetics of drug release. The method described by Korsemeyer and Peppas was used to describe mechanism of drug release.

\section{Comparison of dissolution profiles for selection of optimum batch}

The similarity factor $\left(f_{2}\right)$ given by SUPAC guidelines for modified release dosage forms was used to compare dissolution profiles. The dissolution profiles are considered to be similar when $\mathrm{f}_{2}$ is between 50 and 100 . The dissolution profile of products were compared using $\mathrm{f}_{2}$, which is calculated from following formula,

$$
\mathrm{f}_{2}=50 \times \log \left\{\left[1+\left(\frac{1}{\mathrm{n}}\right) \sum_{\mathrm{t}=1}^{\mathrm{n}} \mathrm{w}_{\mathrm{t}}\left(\mathrm{R}_{\mathrm{t}}-\mathrm{T}_{\mathrm{t}}\right)^{2}\right]^{-0.5} \times 100\right\}
$$

Where, $\mathrm{n}$ is the dissolution time and $\mathrm{R}_{\mathrm{t}}$ and $\mathrm{T}_{\mathrm{t}}$ are the reference (here it is theoretical dissolution profile of famotidine) and test dissolution value at time t. ${ }^{[25]}$

\section{Fourier transform infrared spectroscopy}

Fourier transform infrared (FTIR) spectra of famotidine, HPMC K4M, Gelucire 43/01 and a physical mixture of these ingredients were recorded using $\mathrm{KBr}$ mixing method on FTIR instrument available at central instrument laboratory of the institute (FTIR1700, Shimadzu, Kyoto, Japan).

\section{Table 3: Formulation and evaluation of batches in $3^{2}$ full factorial design}

\begin{tabular}{|c|c|c|c|c|c|c|}
\hline Batch code & $\begin{array}{c}\text { Variable levels i } \\
X_{1}\end{array}$ & $\begin{array}{l}\text { coded form } \\
X_{2}\end{array}$ & BLT(s) & $Q_{1}$ & $\mathbf{Q}_{6}$ & $\mathbf{Q}_{12}$ \\
\hline$\overline{F 1}$ & -1 & -1 & 68 & 25.37 & 72.23 & 101.04 \\
\hline $\mathrm{F} 2$ & -1 & 0 & 71 & 16.02 & 52.6 & 93.22 \\
\hline F3 & -1 & 1 & 117 & 16.39 & 64.2 & 90.59 \\
\hline $\mathrm{F} 4$ & 0 & -1 & 84 & 10.76 & 59.37 & 90.28 \\
\hline $\mathrm{F} 5$ & 0 & 0 & 62 & 23.77 & 63.02 & 92.56 \\
\hline F6 & 0 & 1 & 134 & 14.78 & 67.88 & 101.44 \\
\hline $\mathrm{F} 7$ & 1 & -1 & 106 & 16.46 & 99.16 & 100.00 \\
\hline F8 & 1 & 0 & 63 & 27.05 & 97.99 & 100.00 \\
\hline F9 & 1 & 1 & 178 & 64.37 & 95.88 & 100.00 \\
\hline Coded values & Actual ve & alues & & & & \\
\hline & $\mathrm{X}_{1}$ & $\mathrm{X}_{2}$ & & & & \\
\hline-1 & $10 \%: 30 \%$ & Lactose & & & & \\
\hline 0 & $20 \%: 20 \%$ & MCC & & & & \\
\hline 1 & $30 \%: 10 \%$ & $\mathrm{DCP}$ & & & & \\
\hline
\end{tabular}

All batches contained 40 milligrams of Famotidine, $20 \mathrm{mg}$ sodium bicarbonate, $4 \mathrm{mg}$ talc, $2 \mathrm{mg}$ magnesium stearate $\mathrm{X}_{1}$ indicates the ratio of Gelucire $43 / 01(\%)$ : HPMC $\mathrm{K}_{4} \mathrm{M}(\%)$; $\mathrm{X}_{2}$, type of filler. MCC and DCP indicate microcrystalline cellulose and dicalcium phosphate respectively. $\mathrm{Q}_{1}, \mathrm{Q}_{1}$, and $\mathrm{Q}_{12}$ indicate percentage drug released after 1,6 and 12 hours, respectively. BLT indicates Buoyancy lag time.

\section{Table 4: Results of factorial design batches $\left(F_{1}-F_{9}\right)$}

\begin{tabular}{|c|c|c|c|c|c|c|c|c|c|}
\hline Parameter & $F_{1}$ & $\mathbf{F}_{2}$ & $\mathbf{F}_{3}$ & $\mathbf{F}_{4}$ & $\mathbf{F}_{5}$ & $F_{6}$ & $\mathbf{F}_{7}$ & $F_{8}$ & $F_{9}$ \\
\hline Buoyancy lag time (sec) & 68 & 71 & 117 & 84 & 62 & 134 & 106 & 63 & 178 \\
\hline Assay (\%) & 103.5 & 100.4 & 100.7 & 102.1 & 97.62 & 101.08 & 104.2 & 99.74 & 102.6 \\
\hline Friability (\%) & 0.148 & 0.020 & 0.289 & 0.91 & 0.90 & 0.570 & 0.572 & 0.430 & 0.862 \\
\hline Hardness $\left(\mathrm{Kg} / \mathrm{cm}^{2}\right)$ & 2 & 2.75 & 2.25 & 2 & 2.75 & 2 & 1.5 & 1.75 & 1.5 \\
\hline Similarity factor $\left(f_{2}\right)$ & 59.57 & 61.12 & 68.90 & 54.59 & 83.01 & 58.60 & 38.31 & 29.41 & 32.24 \\
\hline
\end{tabular}




\section{Temperature sensitivity study}

To determine change in in vitro release profile and buoyancy behavior on storage, a temperature sensitivity study of the optimal batch was performed at $40^{\circ} \mathrm{C}$ in humidity jar with $75 \%$ relative humidity $(\mathrm{RH})$. Samples were withdrawn at 1 month interval and evaluated for any change in in vitro drug release pattern and buoyancy behavior.

\section{RESULTS AND DISCUSSION}

\section{Results of preliminary screening}

Gelucire 43/01 was selected as a hydrophobic meltable material to impart sufficient integrity to the tablets. HPMC K4M (hydrophilic) was selected as a matrixing agent considering its widespread applicability and excellent gelling activity in sustained release formulations. Sodium bicarbonate generates $\mathrm{CO}_{2}$ gas in a presence of hydrochloric acid present in dissolution medium. Generated gas is trapped and protected within a gel formed by hydration of HPMC K4M, thereby decreasing the density of tablet. As a density of tablet fall below 1 (density of water), the tablet becomes buoyant. Three batches (CO1, CO2, CO3) as shown in Table 1, were prepared using same amount of polymer Gelucire 43/01 and HPMC K4M while different amount of sodium bicarbonate $(5 \%, 10 \%, 15 \%)$. From the evaluation results [Table 1] it was observed that as the amount of sodium bicarbonate increased from $5 \%$ to $15 \%$, BLT was decreased. At higher amount of sodium bicarbonate, a tablet remained intact only for $10 \mathrm{~h}$ and lost the matrix integrity. Batch containing $10 \%$ sodium bicarbonate remained buoyant and intact for $24 \mathrm{~h}$. Hence $10 \%$ of sodium bicarbonate was considered to be optimum. Three batches (PO1, PO2, PO3) as shown in Table 2, were prepared using $10 \%$ of sodium bicarbonate and different amount of polymer (30\%, 40\%, 50\%). Formulations $\mathrm{PO} 1, \mathrm{PO} 2$, and $\mathrm{PO} 3$ were subjected to in vitro dissolution study. All formulations exhibited buoyancy lag time of less than 100 sec. Tablets of batch PO2 retained integrity throughout a study and released the drug in controlled manner (100.8 CPR in 11 $\mathrm{h}$ as shown in Figure 1. Tablets of batch PO1 did not maintain integrity) and released more than $90 \%$ of a drug in $6 \mathrm{~h}$. Tablets of batch PO3 released only $80.2 \%$ drug in $12 \mathrm{~h}$, which may be due to higher amount of polymer. Hence it was decided to keep total polymer concentration at $40 \%$ for acceptable formulation in further study.

\section{Full factorial design}

A statistical model incorporating interactive and poly nominal terms was used to evaluate the responses.

$\mathrm{Y}=\mathrm{b}_{0}+\mathrm{b}_{1} \mathrm{X}_{1}+\mathrm{b}_{2} \mathrm{X}_{2}+\mathrm{b}_{12} \mathrm{X}_{1} \mathrm{X}_{2}+\mathrm{b}_{11} \mathrm{X}_{1}^{2}+\mathrm{b}_{22} \mathrm{X}_{2}^{2}$

Where $\mathrm{Y}$ is the dependent variable, $\mathrm{b}_{0}$ is the arithmetic mean response of the 9 runs, and $b_{1}$ is the estimated coefficient for the factor $\mathrm{Xi}$. The main effects $\left(\mathrm{X}_{1}\right.$ and $\left.\mathrm{X}_{2}\right)$ represent the average result of changing one factor at a time from its low to high values. The interaction terms $\left(\mathrm{X}_{1} \mathrm{X}_{2}\right)$ show how the response changes when two factors are simultaneously changed. The polynomial terms $\left(\mathrm{X}_{1}^{2}\right.$ and $\left.\mathrm{X}_{2}^{2}\right)$ are included to investigate nonlinearity. Dissolution profile for 9 batches showed a wide variation (i.e., initial $1 \mathrm{~h}$ release ranging from $14.78 \%$ to $64.37 \%$ and drug released after $12 \mathrm{~h}$ ranging from $90.28 \%$ to $101.44 \%$ ) [Figure 2]. Dissolution data indicated that drug release is strongly dependent on the selected independent variables. The coefficients for fitted equations (full and reduced) relating the responses, BLT, $\mathrm{Q}_{1}$, $\mathrm{Q}_{6}$ and $\mathrm{Q}_{12}$ to the transformed factors are shown in Table 3. These polynomial equations can be used to draw conclusion after considering a magnitude of coefficient and the mathematical sign it carries (i.e., negative or positive). Table 5 shows the results of analysis of variance (ANOVA), which was performed to identify insignificant factors. The data were analyzed using Microsoft Excel.

$\mathrm{R}^{2}$ value for BLT, $\mathrm{Q}_{1}$, and Q6 are 0.9082, 0.8637, 0.9331, respectively indicating good correlation between dependent and independent variables. Low $\mathrm{R}^{2}$ value for $\mathrm{Q}_{12}(0.485)$ indicates that drug release at $12 \mathrm{~h}$ is less dependent on selected variables. Reduced models were developed for response variables by omitting the insignificant terms with $P>0.05$. The terms with $P<0.05$ were considered statistically significance and retained in the reduced model. The coefficients for full and reduced models for response variables are shown in Table 5. The coefficients of independent variables for $\mathrm{Q}_{1}$ and $\mathrm{Q}_{12}$ were found - insignificance at $P>0.05$ with out any contribution in prediction of $\mathrm{Q}_{1}$ and $\mathrm{Q}_{12}$.

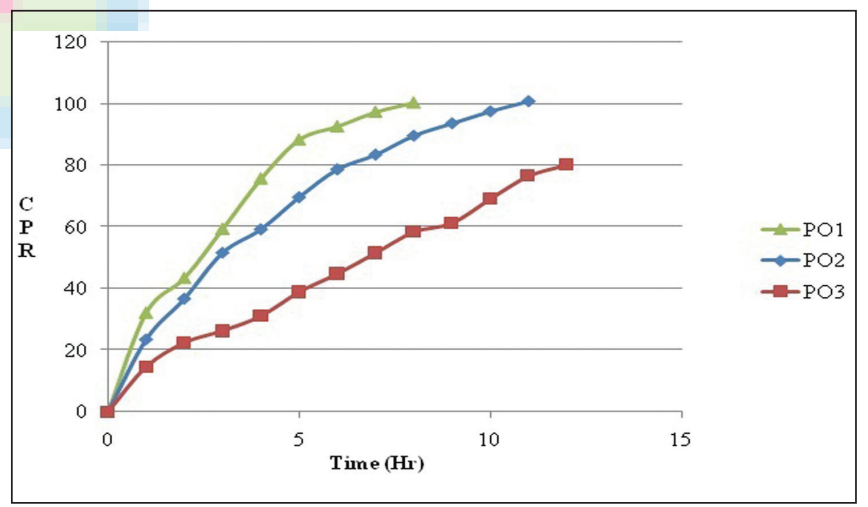

Figure 1: In vitro dissolution profile of batch $\mathrm{PO} 1, \mathrm{PO} 2$, and $\mathrm{PO} 3$

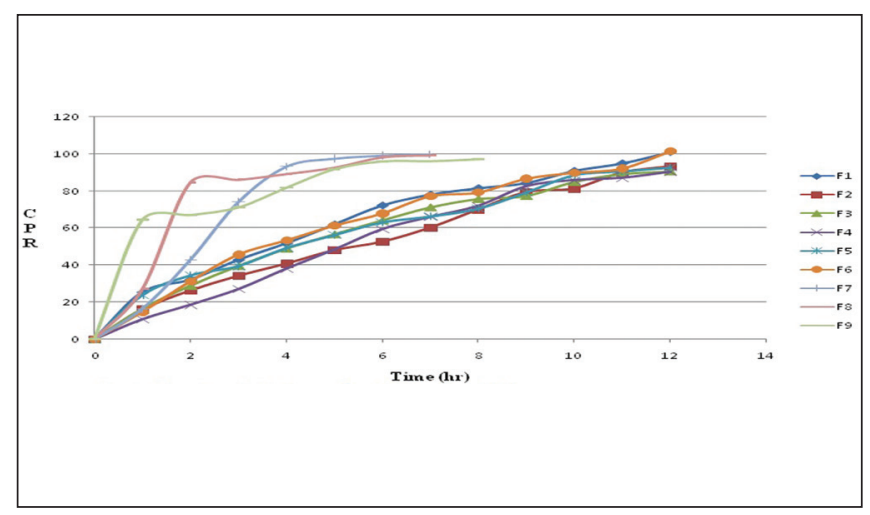

Figure 2: In vitro dissolution profile of formulation F1-F9 


\section{Full and reduced model for BLT}

Significance levels of coefficients $b_{1}, b_{12}$ and $b_{11}$ were found to be $P=0.153,0.597$, and 0.639 , respectively, hence they were omitted from a full model to generate the reduced model. Results of statistical analysis are shown in Table 5. Coefficients $b_{0} b_{2}$, and $\mathrm{b}_{22}$ were found to be significant at $P<0.05$; hence they were retained in a reduced model. Reduced model was tested in proportion to determine whether coefficients $b_{1}, b_{12}$ and $b_{11}$ contribute significance information in a prediction of BLT or not. ${ }^{[26]}$ The results of model testing are shown in Table 6 . The critical value of $F$ for $\alpha=0.05$ is equal to 9.28 ( $\mathrm{df}=3,3$ ). Since a calculated value $\left(\mathrm{F}_{\mathrm{cal}}=1.41\right)$ is less than the critical value $\left(\mathrm{F}_{\mathrm{cri}}\right.$ $=9.28)$, it was concluded that coefficients $b_{1}, b_{12}$, and $b_{11}$ did not contribute significantly in the prediction of BLT and could be omitted from full model to generate-reduced model.

Full and reduced model for $Q_{6}$

Significance levels of coefficients $b_{2}, b_{12}$, and $b_{22}$ were found to be $P=0.890,0.776$, and 0.402 , respectively, hence they were omitted from a full model to generate the reduced model. Results of statistical analysis are shown in Table 5 . Coefficients $b_{0} b_{1}$, and $\mathrm{b}_{11}$ were found to be significant at $P<0.05$; hence they were retained in a reduced model. Reduced model was tested in proportion to determine whether coefficients $b_{2}, b_{12}$, and $b_{22}$ contribute significance information in a prediction of $\mathrm{Q}_{6}$ or not. The results of model testing are shown in Table 6 . The critical value of $\mathrm{F}$ for $\alpha=0.05$ is equal to 9.28 ( $\mathrm{df}=3,3$ ). Since a calculated value $\left(\mathrm{F}_{\mathrm{cal}}=0.355\right)$ is less than the critical value $\left(\mathrm{F}_{\mathrm{cri}}\right.$ $=9.28)$, it was concluded that coefficients $b_{2}, b_{12}$, and $b_{22}$ did not contribute significantly in a prediction of $\mathrm{Q}_{6}$ and could be omitted from full model to generate-reduced model.

\section{Kinetic modeling of dissolution data}

Kinetics of dissolution data were well fitted to zero order, Higuchi model, and Korsemeyer-Peppas model as evident from regression coefficients [Table 7]. In a case of -controlled

\begin{tabular}{|c|c|c|c|c|c|c|}
\hline \multicolumn{7}{|c|}{ For buoyancy lag time } \\
\hline Response (BLT) & $\mathrm{b}_{0}$ & $\mathrm{~b}_{1}$ & $b_{2}$ & $\mathrm{~b}_{12}$ & $b_{11}$ & $b_{22}$ \\
\hline FM & 60.56 & 15.17 & 28.50 & 5.75 & 7.17 & 49.17 \\
\hline RM & 65.33 & - & 28.5 & - & - & 49.17 \\
\hline \multicolumn{7}{|l|}{ For $Q_{1}$} \\
\hline Response $\left(Q_{1}\right)$ & $\mathrm{b}_{0}$ & $\mathrm{~b}_{1}$ & $b_{2}$ & $\mathrm{~b}_{12}$ & $\mathrm{~b}_{11}$ & $b_{22}$ \\
\hline FM & 14.83 & 8.35 & 7.15 & 14.22 & 11.17 & 2.41 \\
\hline RM & - & - & - & - & - & - \\
\hline \multicolumn{7}{|l|}{ For $Q_{6}$} \\
\hline Response $\left(Q_{6}\right)$ & $\mathrm{b}_{0}$ & $b_{1}$ & $b_{2}$ & $\mathrm{~b}_{12}$ & $\mathrm{~b}_{11}$ & $b_{22}$ \\
\hline FM & 59.23 & 17.33 & -0.466 & 1.19 & 16.92 & 5.25 \\
\hline RM & 63.42 & 17.33 & - & - & 16.92 & - \\
\hline \multicolumn{7}{|l|}{ For $Q_{12}$} \\
\hline Response $\left(Q_{12}\right)$ & $\mathrm{b}_{0}$ & $\mathrm{~b}_{1}$ & $\mathrm{~b}_{2}$ & $\mathrm{~b}_{12}$ & $b_{11}$ & $b_{22}$ \\
\hline FM & 93.45 & 2.53 & 0.118 & 2.62 & 2.71 & 1.97 \\
\hline RM & - & - & - & - & & - \\
\hline
\end{tabular}

FM = Full model, RM = Reduced model, BLT= Buoyancy lag time

\begin{tabular}{|c|c|c|c|c|c|c|}
\hline \multicolumn{7}{|c|}{ For buoyancy lag time } \\
\hline & DF & SS & MS & $\mathrm{F}$ & $\mathrm{R}^{2}$ & \\
\hline Regression & & & & & & Fcalc. $=1.41$ \\
\hline FM & 5 & 11323.36 & 2264.67 & 5.94 & 0.9082 & Ftable $=9.28$ \\
\hline $\mathrm{RM}$ & 2 & 9708.22 & 4854.11 & 10.55 & 0.7787 & $\mathrm{DF}(3,3)$ \\
\hline \multicolumn{7}{|l|}{ Error } \\
\hline FM & 3 & 1143.52 & 381.17 & & & \\
\hline RM & 6 & 2758.68 & 459.78 & & & \\
\hline \multicolumn{7}{|l|}{ For $\mathrm{Q}^{6}$} \\
\hline & DF & SS & MS & $\mathrm{F}$ & $\mathrm{R}^{2}$ & \\
\hline Regression & & & & & & Fcalc. $=0.355$ \\
\hline FM & 5 & 2437.31 & 487.46 & 8.37 & 0.9331 & Ftable $=9.28$ \\
\hline $\mathrm{RM}$ & 2 & 2375.24 & 1187.62 & 30.10 & 0.9093 & $\mathrm{DF}(3,3)$ \\
\hline \multicolumn{7}{|l|}{ Error } \\
\hline FM & 3 & 174.70 & 58.23 & & & \\
\hline $\mathrm{RM}$ & 6 & 236.77 & 39.46 & & & \\
\hline
\end{tabular}

DF indicates degree of freedom; SS, sum of squares; MS, mean of squares; R2, regression coefficient; FM, Full model; RM, Reduced model 


\begin{tabular}{|c|c|c|c|c|c|c|c|c|c|}
\hline & $F_{1}$ & $F_{2}$ & $F_{3}$ & $F_{4}$ & $F_{5}$ & $F_{6}$ & $F_{7}$ & $F_{8}$ & $F_{9}$ \\
\hline \multicolumn{10}{|c|}{ Zero order } \\
\hline$B$ & 21.85 & 11.91 & 17.67 & 5.89 & 21.30 & 18.18 & 41.91 & 61.54 & 64.44 \\
\hline A & 7.03 & 6.93 & 6.69 & 7.71 & 6.32 & 7.35 & 6.30 & 4.11 & 3.34 \\
\hline $\mathrm{R}^{2}$ & 0.9879 & 0.9979 & 0.9796 & 0.9874 & 0.9914 & 0.9798 & 0.7812 & 0.6685 & 0.9030 \\
\hline \multicolumn{10}{|c|}{ First order } \\
\hline$B$ & 1.44 & 1.28 & 1.34 & 1.14 & 1.43 & 1.36 & 1.55 & 1.74 & 1.82 \\
\hline$A$ & 0.053 & 0.063 & 0.059 & 0.049 & 0.050 & 0.062 & 0.050 & 0.029 & 0.017 \\
\hline $\mathrm{R}^{2}$ & 0.9520 & 0.9563 & 0.9126 & 0.9324 & 0.9590 & 0.8887 & 0.7082 & 0.5981 & 0.8975 \\
\hline \multicolumn{10}{|c|}{ Higuchi } \\
\hline$B$ & -10.60 & -19.22 & -13.97 & -29.53 & -7.52 & -16.52 & 6.49 & 37.29 & 48.06 \\
\hline$A$ & 32.29 & 31.47 & 31.08 & 35.35 & 28.89 & 34.11 & 31.77 & 21.22 & 15.88 \\
\hline $\mathrm{R}^{2}$ & 0.9957 & 0.9938 & 0.9981 & 0.9934 & 0.9939 & 0.9980 & 0.8636 & 0.7580 & 0.9412 \\
\hline \multicolumn{10}{|c|}{ Hixon Crowell } \\
\hline$B$ & 26.04 & 29.31 & 27.44 & 31.36 & 1.69 & 27.27 & 19.36 & 12.80 & 11.77 \\
\hline A & -2.343 & -2.31 & -2.23 & -2.569 & -0.145 & -2.44 & -2.10 & -1.37 & -1.11 \\
\hline $\mathrm{R}^{2}$ & -0.9876 & -0.9978 & -0.9795 & -0.9874 & -0.9742 & -0.9797 & -0.7813 & -0.6684 & -0.9030 \\
\hline \multicolumn{10}{|c|}{ Korsemeyer and Peppas } \\
\hline B & -0.630 & -0.801 & -0.753 & -0.978 & -0.638 & -0.756 & -0.598 & -0.362 & -0.212 \\
\hline $\mathrm{N}$ & 0.590 & 0.705 & 0.692 & 0.905 & 0.559 & 0.738 & 0.675 & 0.412 & 0.202 \\
\hline $\mathrm{R}^{2}$ & 0.9938 & 0.9998 & 0.9955 & 0.9962 & 0.9960 & 0.9867 & 0.8954 & 0.7952 & 0.9523 \\
\hline
\end{tabular}

or sustained release formulation, diffusion, swelling and erosion are the three most important rate controlling mechanisms. Formulation containing swelling polymers shows swelling as well as diffusion mechanism because a kinetic of swelling includes relaxation of polymer chains and imbibitions of water, causing the polymer to swell and changing it from glassy to rubbery state. Diffusion exponent $\mathrm{n}$ is an indicative of mechanism of drug release from the formulation. For a swellable cylindrical (tablet) drug delivery system, the $\mathrm{n}$ value of 0.45 is indicative of Fickian diffusion controlled drug release. Value of $\mathrm{n}$ between 0.5 and 0.85 signifies anomalous (non-Fickian) transport, $\mathrm{n}$ value of 0.85 indicates case II transport, and $\mathrm{n}$ value greater than 0.85 indicates super case II transport. ${ }^{[27,28]}$ Value of diffusion exponent $\mathrm{n}$ for most factorial formulations is between 0.5 and 0.85 [Table 7] indicating non-Fickian drug release from the formulations.

\section{Comparison of dissolution profiles for selection of optimum batch}

Values of similarity factor $\left(f_{2}\right)$ for batches $F_{1}$ to $F_{6}$ were greater than 50 compared with theoretical dissolution profile [Table 4] indicating good similarity in dissolution. Tablets of batch $\mathrm{F}_{5}$ showed maximum value of $\mathrm{f}_{2}$ (83.01), hence was selected as optimum batch. The tablets of batch $\mathrm{F}_{5}$ were subjected to the temperature sensitivity study.

\section{Fourier transform infrared spectroscopy}

Drug excipients interactions play a vital role in the release of drug from formulation. Fourier transform infrared spectroscopy has been used to study physical and chemical interactions between a drug and the excipients used. The pure famotidine and its mixture with
Gelucire 43/01 and HPMC K4M was mixed separately with IR grade $\mathrm{KBr}$ and were scanned over a range of $400-4500 \mathrm{~cm}^{-1}$ using FTIR instrument (FTIR-1700, Shimadzu, Kyoto, Japan). The drug exhibits peak due to primary amine and alkene group. It was observed that there were no changes in these main peaks in IR spectra of a mixture of drug and polymers [Figures 3-6]. The FTIR study revealed no physical or chemical interactions of famotidine with Gelucire 43/01 and HPMC K4M as evident from Figure 6.

\section{Results of temperature sensitivity study}

To determine any change in in vitro release profile on storage, a temperature sensitivity study of the optimal batch $\mathrm{F}_{5}$ was performed at $40^{\circ} \mathrm{C}$ in humidity jar with $75 \% \mathrm{RH}$. Sample withdrawn after 1 month showed no significant change in in vitro buoyancy and in vitro drug release pattern.

\section{CONCLUSION}

From present investigation it was concluded that a combined matrix system containing hydrophobic and hydrophilic polymer minimized bust release of drug from tablet and achieved drug release by zero order kinetic, which is practically difficult with only hydrophilic matrix.

\section{ACKNOWLEDGMENTS}

The authors thank Gattefosse for a gift sample of Gelucire 43/01, Mann Pharmaceuticals Limited, Mehsana, for a gift sample of famotidine. Authors also thank Shri Sarvajanik Pharmacy College, Mehsana, for providing all other ingredients and the required infrastructure for conducting this research work. 


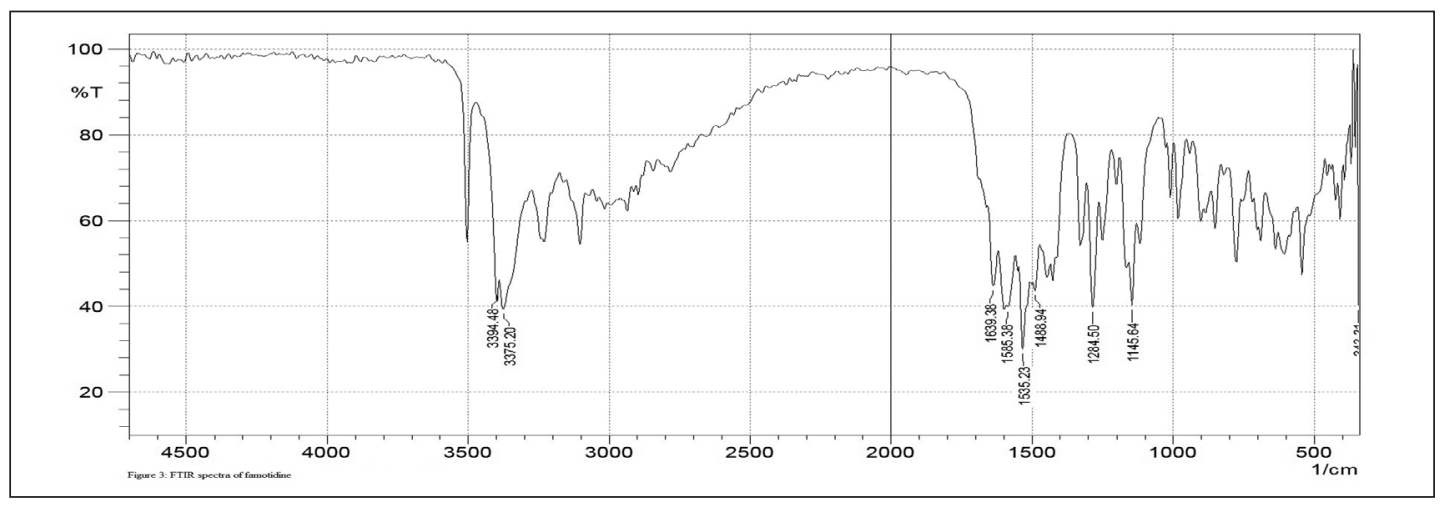

Figure 3: FTIR spectra of Famotidine

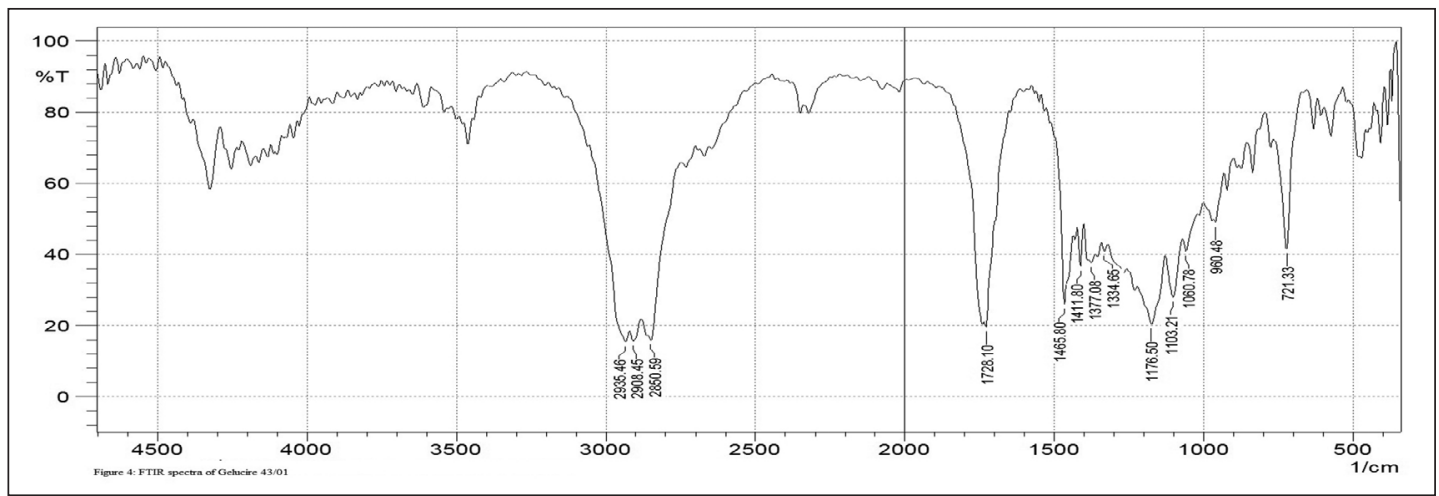

Figure 4: FTIR spectra of Gelucire 43/01

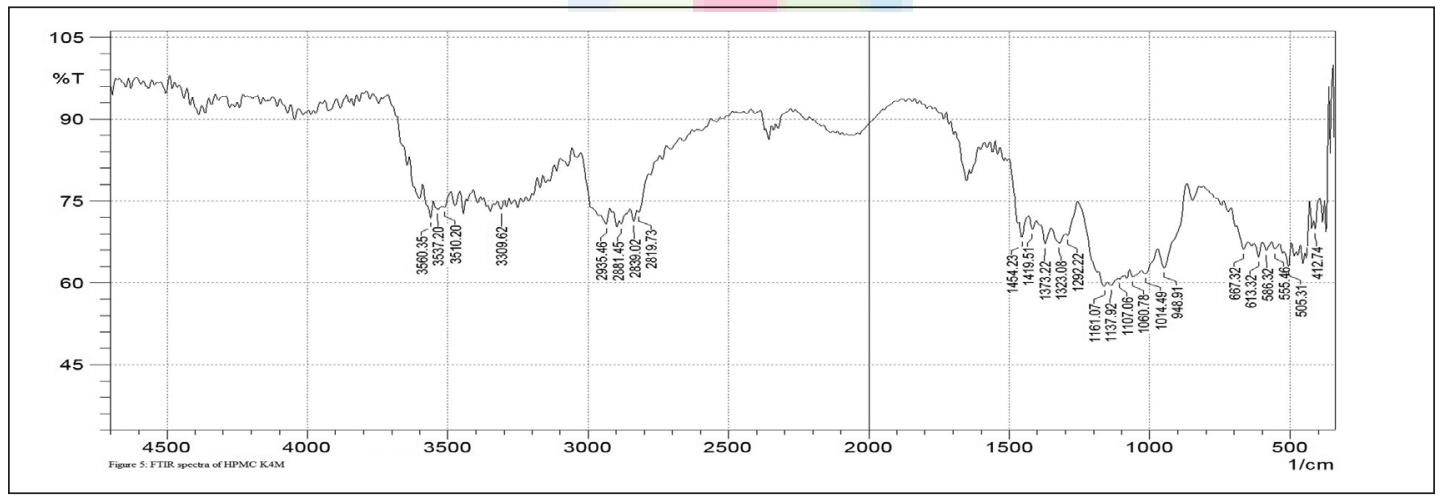

Figure 5: FTIR spectra of HPMC K4M

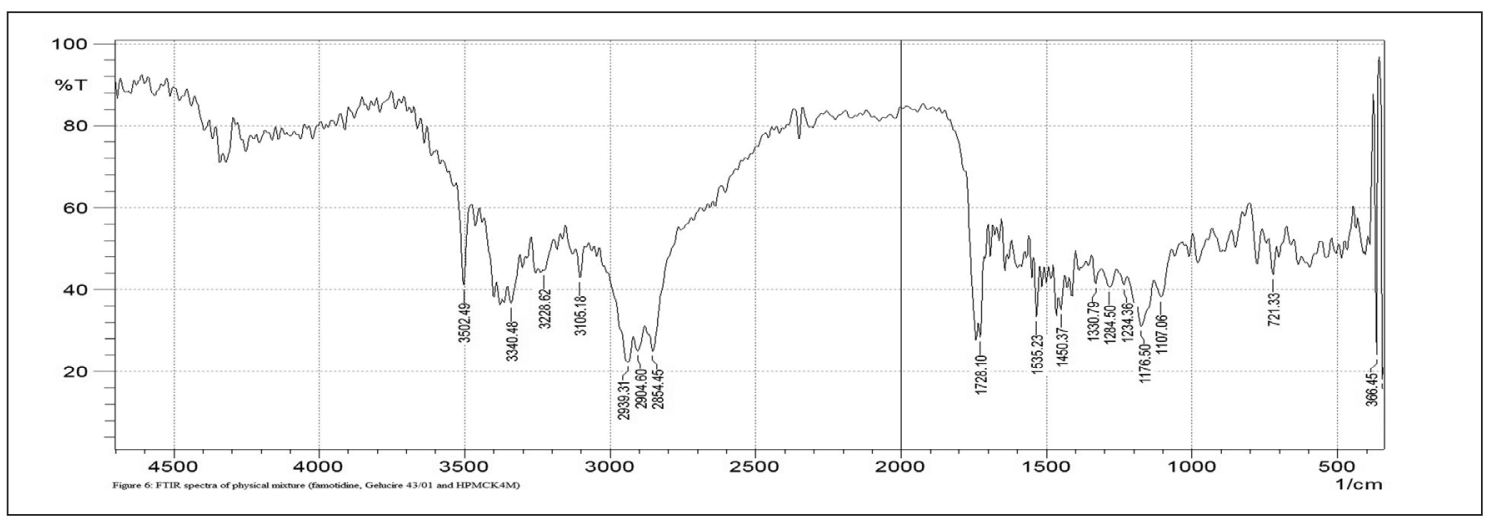

Figure 6: FTIR spectra of physical mixture (Famotidine, Gelucire 43/01 and HPMC K4M) 


\section{REFERENCES}

1. Sood A, Panchagnula R. Design of controlled release delivery systems using a modified pharmacokinetic approach: A case study for drugs having a short elimination half-life and a narrow therapeutic index. Int J Pharm 2003;261:27-41.

2. Kim KH, Singh BN. Floating drug delivery system an approach to oral controlled drug delivery via gastric retention. J Control Release 2000;63:235-359.

3. Bardonnet PL, Faivre V, Pugh WJ, Piffaretti JC, Falson F. Gastroretentive dosage forms: Overview and special case of Helicobacter pylori. J Control Release 2006;111:1-18.

4. Klausner EA, Lavy E, Friedman M, Hoffman A. Expandable gastroretentive dosage form. J Control Release 2003;90:143-62.

5. Reynolds JE. Gastro-intestinal agents. In: Kathleen Parfitt, editors. Martindale, the extra pharmacopoeia, $31^{\text {st }}$ ed. London: The Royal Pharmaceutical Society; 1996. p. 1218-20.

6. Willemjntje A, Hoogerwerf, Pasrich PJ. Agents for control of gastric acidity and treatment of peptic ulcers and gastrooesophageal reflux disease. In: Hardman J, editors. Goodman and Gilman's "The Pharmacological Basis of Therapeutics". $10^{\text {th }}$ ed. New York: The MC Graw Hill; 2001. p.1741.

7. Chien YW. Fundamentals of controlled drug administration. In: Swarbrick J. Novel drug delivery system. $2^{\text {nd }}$ ed. New York, Basel; Marcel Dekker. Inc; 1982. p. 465-574.

8. Conte U, Maggi L, Colombo P, Manna AL. Multilayered hydrophilic matrices as constant release devices. J Control Release 1993;26:39-47.

9. Behzad S, Taybeh J, Fakher R, Mohmmad R. Multiple unite sustained released floating of sodium diclofenac: Formulation and evaluation using factorial design. Int $\mathrm{J}$ Drug Deliv 2010;2:344-51.

10. Thakkar VT, Shah PA, Soni TG, Parmar MY, Gohel MC, Gandhi TR. Fabrication and evaluation of levofloxacin hemihydrates floating tablet. Res In Pharma Sci 2008;3:1-8.

11. Lakade $\mathrm{SH}$, Bhalekar MR. Formulation and evaluation of sustained release matrix tablet of anti-anginal Drug: Influence of combination of hydrophobic and hydrophlic matrix former. Res J Pharm Tech 2008;1:410-3.

12. Kar RK, Mohapatra S, Barik BB. Design and characterization of controlled release matrix tablets of zidovudine. Asian $\mathrm{J}$ Pharm Clin Res 2009;2:54-61.

13. Ravisankar V, Reddy YD, Rao AN, Dhachinamoorthy D, Chandrasekhar KB. Effect of hydrophilic and hydrophobic polymers on losartan potassium matrix tablet. J Pharm Res 2010;3:2195-7.

14. Conte $U$, Maggi L. Modulation of the dissolution profiles from
GeomatrixR multilayer matrix tablets containing drugs of different solubility. Biomaterials 1996;17:889-96.

15. Conte $U$, Maggi L. A flexible technology for the linear, pulsatile release of drugs, allowing for easy accommodation of difficult in vitro targets. J Control Release 2000;64:263-8.

16. Conte $\mathrm{U}$, Maggi L. Multilayer tablets as drug delivery devices. Pharm Tech Int 1998;10:174-82.

17. Krögel I, Bodmeier R. Development of a multifunctional matrix drug delivery system surrounded by an impermeable cylinder. J Control Release 1999;61:43-50.

18. Colombo P, Conte U, Gazzaniga A, Maggi L, Sangalli ME, Manna $A L$, et al. Drug release modulation by physical restrictions of matrix swelling. Int J Pharm 1990;63:43-8.

19. Danckwerts MP. Optimization and development of a coreincup tablet for modulated release of theophylline in simulated gastrointestinal fluids. Drug Dev Ind Pharm 2000;26:767-72.

20. Tiwari SB, Pai MR, Mehta PR, Chaudhary PB, Murhty TK. Controlled release formulation of tramadolol hydrochloride using hydrophilic hydrophobic mixture. AAPS PharmSciTech 2003;4:31.

21. Xu X, Sun M, Zhi F, Hu Y. Floating matrix dosage form for phenoporlamine hydrochloride based on gas forming agent: In vitro and in vivo evaluation in healthy volunteers. Int J Pharm 2006;310:139-45.

22. Higuchi T. Mechanism of sustained action mediation, theoretical analysis of rate of release of solid drugs dispersed in solid matrices. J Pharm Sci 1963;52:1145-49.

23. Hixon AW, Crowell JH. Dependence of reaction velocity upon surface and agitation. Ind Engg Chem 1931;23:923-31.

24. Korsmeyer RW, Gurny R, Doelker E, Buri P, Peppas NA. Mechanism of solute release from porous hydrophillic polymers. Int J Pharm 1983;15:25-35.

25. Coasta P, Manuel J, Labao S. Modelling and comparision of dissolution profiles. Eur J Pharm Sci 2002;13:123-33.

26. Mendenhall W, Sincich T. Multiple regression. A second course in Business statasticals, Regression analysis. $3^{\text {rd }}$ ed. San Francisco, CA: Dellen Publishing Co; 1989. p. 141-226.

27. Siepmam J, Peppas NA. Modelling of drug release from delivery system based on hydroxylpropyl methylcellulose. Adv Drug Deliv Rev 2001:48:139-57.

28. Ritger PL, Peppas NA. A simple equation for description of solute release from swellable device. J Control Release 1987;5:7-42.

How to cite this article: Patel DM, Patel MJ, Patel AN, Patel CN. Formulation and evaluation of mixed matrix gastro-retentive drug delivery for famotidine. Int J Pharma Investig 2011;1:247-54.

Source of Support: Nil. Conflict of Interest: None declared.

Announcement

Android App

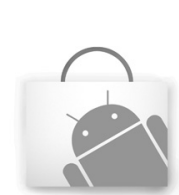

\section{Download Android application}

A free application to browse and search the journal's content is now available for Android based mobiles and devices. The application provides "Table of Contents" of the latest issues, which are stored on the device for future offline browsing. Internet connection is required to access the back issues and search facility. The application is compatible with all the versions of Android. The application can be downloaded from https://market.android.com/details?id=comm.app.medknow. For suggestions and comments do write back to us. 